\title{
PRIORITIZATION OF HAZARDS BY MEANS OF A QFD- BASED PROCEDURE
}

\author{
MARA LOMBARDI \& MARIO FARGNOLI \\ Faculty of Civil and Industrial Engineering, of the Sapienza University of Rome, Italy.
}

\begin{abstract}
Despite the evolution of regulations in the field of occupational health and safety promoted in EU countries, the number of accidents and victims has not significantly decreased in recent years, especially in constructions and agriculture sectors, as underlined by official reports of the Italian Workers' Compensation Authority. Main reasons of such a situation are due to the characteristics of working activities in these sectors. The variety of operations, the frequent exchange of tasks among workers within the same company, the continuous change of workplaces, the frequent exchange of workers for the same activity (e.g. seasonal workers), and the workers' stress caused by seasonal jobs. For these reasons both risk assessment and safety management activities result in being more difficult than in other working sectors. Thus, it is important to provide methodologies and tools that allow companies to carry out these tasks more effectively. In such a context, the study proposed by Esra Bas in 2014 certainly represents an attempt to provide a supporting methodology for engineers engaged in risk assessment activities. This approach consists in the use of the Quality Function Deployment (QFD) method, and it is aimed at evaluating how specific tasks can be in relationship with specific hazards, which in turn are related to specific events, and finally at defining what preventive/protective measures can be introduced against those events. Based on this, we tried to further investigate such an approach, with the goal of providing an easier-to-use tool, which can be used in risk assessment activities of critical contexts as the agriculture one. With this aim in mind, a case study concerning the risk assessment of an agricultural machinery was carried out.
\end{abstract}

Keywords: agricultural equipment, house of quality, machinery safety, occupational safety, quality function deployment, risk assessment

\section{INTRODUCTION}

In last decades, regulations concerning occupational health and safety, as well as machinery safety have become more and more severe. Despite this, in most of EU countries the number of accidents and victims has not significantly decreased [1,2]. Similarly, also in other developed countries such a phenomenon is perceived [3-6]. In particular, considering the Italian context, the occurrence of serious injuries and fatalities is very critical in the agriculture activities, where the compliance with new safety requirements results in being more difficult, due to the specific characteristics of the sector [7]. Actually, it has to be underlined that difficulties related with the implementation of safety measures are numerous, in particular for small and medium sized companies (SMEs), which can hardly afford additional costs for the compliance with safety requirements. SMEs represent more than the $80 \%$ of enterprises operating in the agricultural sector in Italy, and most of them are family-owned companies. Moreover, the number of part-time workers is also consistent.

Most of serious accidents in this sector occur while using self-propelled machines, and in particular tractors [8-11], because of:

- The obsolescence of a large number of machinery still used nowadays, which need to be adapted to the latest safety requirements;

- The lack of knowledge of safety rules when using these machines, including correct procedures when carrying out maintenance activities and setting-up operations. 
Thus, it is clear that both risk assessment and safety management activities result in being more difficult than in other working sectors. For these reasons, the development of methodologies and tools that allow companies to carry out these tasks more efficaciously is discussed in literature, e.g. in Refs. [12-16]. Also the involvement of both users and equipment providers of agriculture machinery is important to properly analyse risk factors and the effectiveness on preventive and protective measures adopted, since it is recognized that most of occupational accidents are caused by unsafe conditions and unsafe behaviours [14, 17-21]. Therefore, performing risk assessment in a sequential manner (i.e. cause-effect analysis) is insufficient to take into account such a complexity. As argued by Ref. [22], a holistic approach is needed to include interactions among different agents (operators, technical systems, working environment). In such a context, the study proposed by Ref. [1] certainly represents an attempt to provide a supporting methodology for engineers engaged in risk evaluations. On these considerations, to further investigate the use of the Quality Function Deployment method in safety risk management, the paper presents a practical case study concerning the risk analysis of an agricultural tractor taking into account its multiple uses options.

The remainder of the paper is organized as follows. In Section 2 a background analysis concerning the occupational accidents trends and safety issues in the agricultural sector is reported. Then Section 3 describes main characteristics of the proposed research approach, while in Section 4 its implementation to a practical case study is shown. Hence results obtained are discussed in Section 5, while Section 6 addresses conclusions and further work.

\section{BACKGROUND ANALYSIS}

In the last years standards and regulations concerning occupational safety have become increasingly strict, following the action of the European Union, aimed at making the framework of safety requisites to protect both consumers and professionals from unsafe products more adequately. In such a context, the New Legislative Framework (NLF) is a clear example of this trend, which is oriented at guaranteeing an equal emphasis on product related requirements to be met when products are placed on the market, as well as on enforcement safety aspects during the whole life-cycle of products [23].

Nevertheless, as mentioned above, the number of accidents has not significantly decreased, especially considering small and medium sized enterprises operating in agriculture and forestry sectors. Latest data concerning the occurrence of occupational accidents in the sector of agriculture [24] show that the problem is very relevant in Italy, considering both its absolute value, as well as the number of accidents occurred in agricultural activities in comparison with the ones registered in other sectors (Table 1). As a matter of facts, these data need to be read considering the number of workers operating in the various sectors, i.e. the frequency factor (number of accidents per 1000 of employees). In this case, in 2015-2016 the frequency factor in industry and services was ca. 4,36, while in agriculture it is more than twice this number.

Table 1: Official statistics on occupational accidents per sector (Source: INAIL, 2017).

\begin{tabular}{lllllll}
\hline Sector & $\mathbf{2 0 1 1}$ & $\mathbf{2 0 1 2}$ & $\mathbf{2 0 1 3}$ & $\mathbf{2 0 1 4}$ & $\mathbf{2 0 1 5}$ & $\mathbf{2 0 1 6}$ \\
\hline Industry and service & $79 \%$ & $78 \%$ & $77 \%$ & $77 \%$ & $78 \%$ & $78 \%$ \\
Agriculture & $6 \%$ & $6 \%$ & $6 \%$ & $6 \%$ & $6 \%$ & $6 \%$ \\
Public & $15 \%$ & $16 \%$ & $17 \%$ & $17 \%$ & $17 \%$ & $16 \%$ \\
Total & $\mathbf{8 1 7 . 7 7 8}$ & $\mathbf{7 4 5 . 5 7 2}$ & $\mathbf{6 9 4 . 9 6 9}$ & $\mathbf{6 6 3 . 4 9 3}$ & $\mathbf{6 3 2 . 6 6 5}$ & $\mathbf{6 3 6 . 8 1 2}$ \\
\hline
\end{tabular}


A more detailed analysis of these data shows that in agriculture also the number of permanent injuries is quite large and the most dangerous activities (considering the number of permanent injuries and fatalities which occurred) are the ones which involve the use of machines and mechanical equipment, and in particular the use of tractors (Table 2). Furthermore, also accidents occurred on the road were considered: in the period January 2016-July 2016, according to ASAPS [25], 243 cases involving tractors were registered, causing 106 fatalities among tractors' drivers and passengers, as well as 162 people injured.

Taking into account data provided by INAIL, the Italian Workers' Compensation Authority [26], it was possible to further analyse the types of accidents occurred while using a tractor during in field working activities. As shown in Table 3, most of them are due to roll-over, running-over and falling.

The analysis of the way events occurred showed that this type of accidents are related to different activities, such as tillage, harvesting and pesticide application, or when the tractor is used as a power unit (i.e. due to an unsafe us of the tractor's power take-off (PTO)). The main reasons of such a situation can be found in the following aspects:

- A large number of tractors used in agricultural activities are not up-dated following the recent development of safety standards and regulations (the average age is more than 20 years old in accordance with data provided by UNACMA (National Union of Agricultural Machinery Dealers)).

- Almost 50\% of operators are part-time workers (i.e. seasonal workers, hobbyists), whose expertise and knowledge of safety procedures is poor (i.e. lack of proper use of PPEs (Personal Protection Equipment), compliance with latest laws and regulations, proper maintenance activities).

Table 2: Trend of fatal accidents in agriculture (Source: INAIL, 2017).

\begin{tabular}{llll}
\hline Year & $\begin{array}{l}\text { Fatal accidents in } \\
\text { agriculture }\end{array}$ & $\begin{array}{l}\text { Fatal accident involving } \\
\text { tractors }\end{array}$ & $\begin{array}{l}\text { Percentage of fatal accident } \\
\text { involving tractors }\end{array}$ \\
\hline 2013 & 199 & 121 & $60.8 \%$ \\
2014 & 189 & 121 & $64.0 \%$ \\
2015 & 205 & 137 & $66.8 \%$ \\
2016 & 197 & 114 & $69.5 \%$ \\
\hline
\end{tabular}

Table 3: Types of fatal accidents involving tractors (Source: INAIL, 2017).

\begin{tabular}{llllllll}
\hline Type & $\mathbf{2 0 1 0}$ & $\mathbf{2 0 1 1}$ & $\mathbf{2 0 1 2}$ & $\mathbf{2 0 1 3}$ & $\mathbf{2 0 1 4}$ & $\mathbf{2 0 1 5}$ & $\mathbf{2 0 1 6}$ \\
\hline Roll-over & 116 & 80 & 85 & 89 & 100 & 106 & 90 \\
Running-over & 9 & 13 & 7 & 13 & 9 & 15 & 9 \\
Falling & 8 & 11 & 6 & 7 & 10 & 10 & 8 \\
Collision & & 5 & 7 & 3 & & 4 & 1 \\
Others & 2 & 18 & 8 & 9 & 2 & 2 & 6 \\
Total & $\mathbf{1 3 5}$ & $\mathbf{1 2 7}$ & $\mathbf{1 1 1}$ & $\mathbf{1 2 1}$ & $\mathbf{1 2 1}$ & $\mathbf{1 3 7}$ & $\mathbf{1 1 4}$ \\
\hline
\end{tabular}


If we consider also difficulties related to the great variety of activities, as well as the continuous change of workplaces, it appears clear why risk assessment and safety management activities in agriculture result in being more difficult than in other working sectors. For these reasons, it is important to provide methodologies and tools that allow companies to carry out these tasks more effectively.

\section{MATERIALS AND METHODS}

The proposed approach is based on the use of the Quality Function Deployment (QFD) method [27], following research hints provided by Bas [1].

QFD is widely recognized as one of the most effective tools for the design and development of products and services. The core of the method relies on the House of Quality (HoQ), i.e. a set of matrices that allows engineers to translate the so-called 'Voice of Customers' (VoCs) into engineering parameters [28]. In Fig. 1 a scheme of the HoQ is shown, where customer requirements ('Whats') are matched with engineering characteristics ('Hows') by means of a relationship matrix. Other parts of the HoQ are two matrices, used to assess relationships among themselves of the Whats and the Hows respectively. The output of the HoQ consists in the assessment of engineering characteristics and in their quantitative definition (i.e. the so-called 'How-muches').

In the last years, the use of QFD has been extended to the improvement of different properties related to products and services, such as: environmental sustainability, reliability, maintainability, etc., while its use in the field of health and safety, and risk assessment has been scarcely investigated as pointed out by some authors [29]. This is due to the fact that main issues and targets concerning safety are defined by laws and regulations (e.g. directive 2006/42/EC in the case of machinery). Hence, whenever a higher level of safety can be achieved it becomes the standard level. Based on this, most of studies on the application of QFD in health and safety field concern the assessment of safety requirements as target values

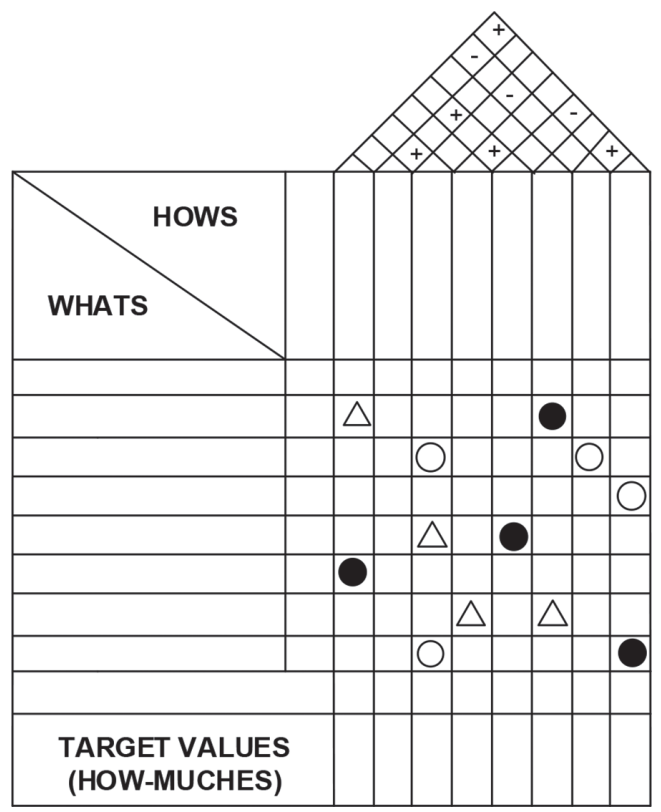

Figure 1: Scheme of the House of Quality (HoQ). 

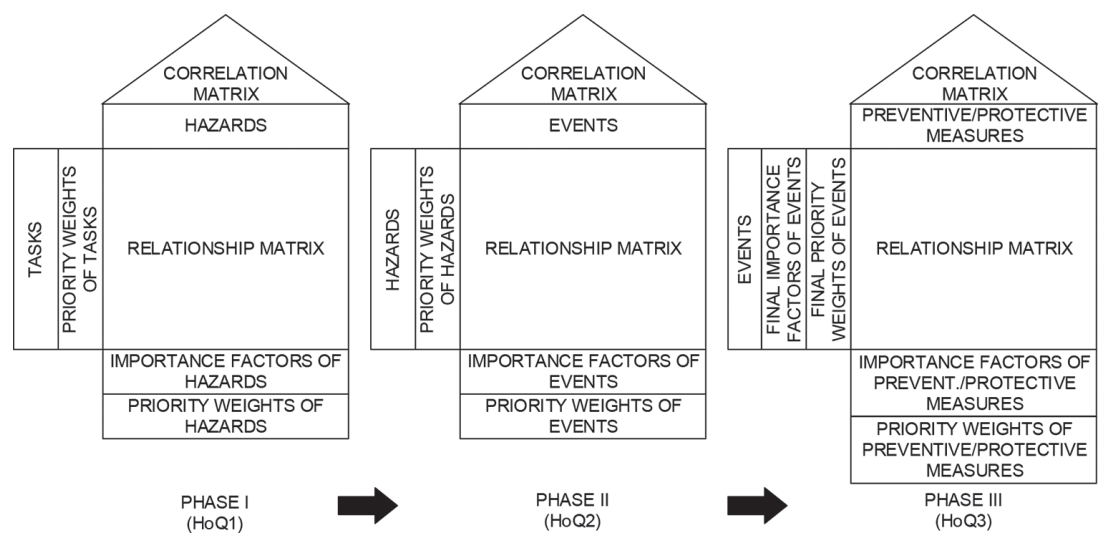

Figure 2: Scheme of the QFD for Safety adapted from Ref. [1].

$[7,29,30]$. A different approach is the one proposed by both Abubakar [8] and Bas [1], who used the 'mechanism' of the HoQ as a tool to assess cause-effects relationships. In particular, the latter presented a three-phase procedure (Fig. 2):

- Phase I - evaluation of the relationships between tasks and hazards;

- Phase II - evaluation of the relationships between hazards and events;

- Phase III - comparison of events with preventive and protective measures.

Such an approach (Fig. 2) was discussed through its hypothetical application in two different contexts: a project in construction industry and an IT firm belonging to SMEs category.

Based on this, we tried to apply it in practice by means of a real case study in the agriculture field with the aim of verifying its effectiveness as a risk assessment tool.

\section{CASE STUDY}

More in details, the risk assessment concerned agricultural activities carried out by a small company that produces wheat using a wheeled cabin tractor and several agricultural machinery and equipment (e.g. trailers, ploughs, harrows, etc.). Main technical characteristics of the tractor are the followings:

- Power: $80 \mathrm{~kW}$.

- Weight: $4000 \mathrm{~kg}$ (un-ballasted).

- Axels: 4WD front axle.

- Wheelbase: $2422 \mathrm{~mm}$.

- Track width (min/max): 1625-2025 mm.

Firstly, the set of tasks of a given project and the possible hazards that may arise from performing these tasks are analyzed. The definition of tasks carried out in collaboration with the company's experts, while hazard identification and assessment was performed with the support of both experts belonging to INAIL, the Italian Workers' Compensation Authority, as well as experts belonging to UNACMA (the Italian Association of Dealers of Agricultural Machinery). The set of the $T_{m}$ tasks and the list of the $h_{n}$ hazards were defined, and their relationships were quantified by means of the $\mathrm{HoQ}_{1}$ (Table 4). 
Table 4: Correlation matrix of the HoQ1.

\begin{tabular}{|c|c|c|c|c|c|c|c|c|c|c|c|}
\hline $\mathrm{HoQ}_{1}$ & 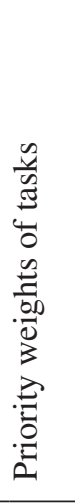 & 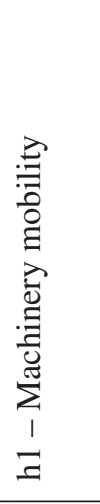 & 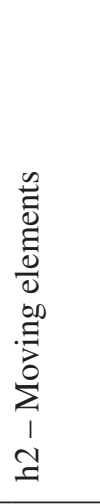 & 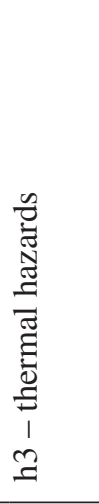 & 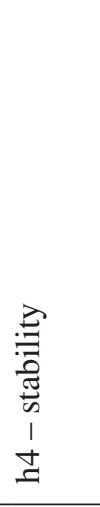 & 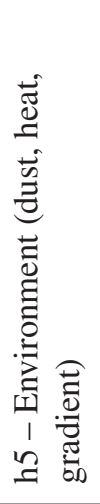 & $\begin{array}{l}0 \\
.0 \\
0 \\
z \\
1 \\
1 \\
0\end{array}$ & 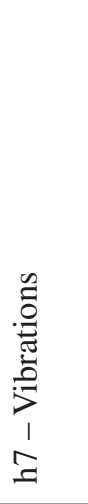 & 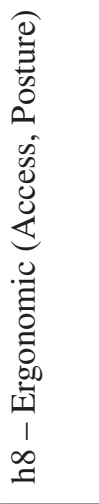 & 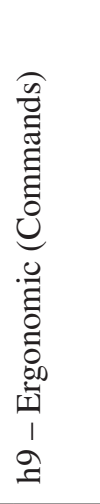 & 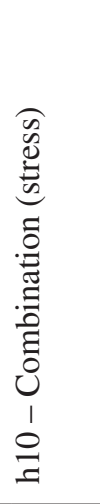 \\
\hline $\mathrm{T} 1$ - Setting & 0.1 & 0 & 3 & 9 & 0 & 0 & 0 & 0 & 0 & 9 & 9 \\
\hline T2 - Trailing & 0.1 & 9 & 0 & 0 & 9 & 0 & 3 & 9 & 9 & 0 & 9 \\
\hline T3 - Ripping & 0.1 & 3 & 3 & 0 & 3 & 3 & 3 & 9 & 3 & 3 & 0 \\
\hline T4 - Plowing & 0.1 & 3 & 3 & 0 & 3 & 3 & 3 & 9 & 3 & 3 & 0 \\
\hline T5 - Tilling & 0.1 & 3 & 3 & 0 & 3 & 3 & 3 & 9 & 3 & 3 & 0 \\
\hline T6 - Shredding & 0.1 & 3 & 3 & 0 & 3 & 3 & 3 & 9 & 3 & 3 & 0 \\
\hline T7 - Sowing & 0.1 & 3 & 3 & 0 & 3 & 3 & 3 & 3 & 3 & 3 & 0 \\
\hline T8 - Mowing & 0.1 & 3 & 9 & 0 & 0 & 9 & 3 & 3 & 3 & 9 & 0 \\
\hline $\begin{array}{l}\text { T9 - Raking } \\
\text { and tedding }\end{array}$ & 0.1 & 9 & 9 & 0 & 0 & 9 & 0 & 3 & 3 & 3 & 3 \\
\hline T10 - baling & 0.1 & 9 & 3 & 0 & 0 & 3 & 0 & 9 & 3 & 9 & 3 \\
\hline \multicolumn{2}{|c|}{$\begin{array}{l}\text { Importance factors of } \\
\text { hazards }\end{array}$} & 4.50 & 3.90 & 0.90 & 2.40 & 3.60 & 2.10 & 6.30 & 3.30 & 4.50 & 2.40 \\
\hline \multicolumn{2}{|c|}{$\begin{array}{l}\text { Priority weights of } \\
\text { hazards }\end{array}$} & 0.652 & 0.565 & 0.130 & 0.348 & 0.522 & 0.304 & 0.913 & 0.478 & 0.652 & 0.348 \\
\hline
\end{tabular}

Similarly, the events that the hazards may cause and their mutual relationship were quantified using the HoQ2 (Table 5).

In the HoQ3, the final importance factors and priority weights of events, as well as the hierarchy of preventive/protective measures were defined (Table 6) and assessed (Table 7). It has to be pointed out that the relationships between the events and preventive/protective measures were quantified by means of the following formula, which provides the final priority weights of events $\left(w_{i}\right)$ :

$$
w_{i}=\left(o_{i, n f} \cdot s_{i, n f}+o_{i, f} \cdot s_{i, f}\right)
$$

where:

$o_{i, n f}$ represents the probability of occurrence of event $e_{i}$ that leads to a non-fatal injury;

$s_{i, n f}$ represents the expected severity of event $e_{i}$ that leads to a non-fatal injury;

$o_{i, f}$ represents the probability of occurrence of event $e_{i}$ that leads to a fatal injury; and

$s_{i, f}$ represents the expected severity of event $e_{i}$ that leads to a fatal injury. 
Table 5: Correlation matrix of the HoQ2.

\begin{tabular}{|c|c|c|c|c|c|c|c|c|c|c|c|c|}
\hline $\mathrm{HoQ}_{2}$ & 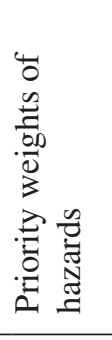 & 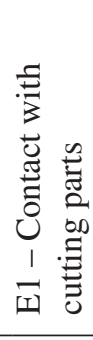 & 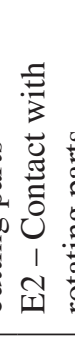 & 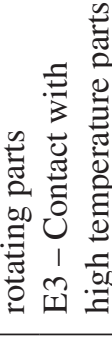 & 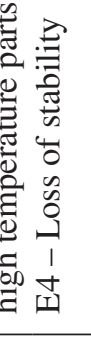 & 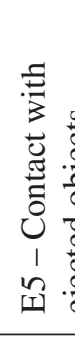 & 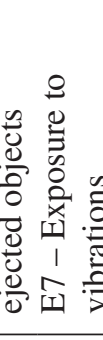 & 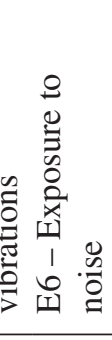 & 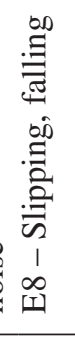 & 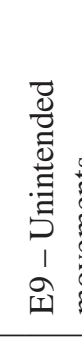 & 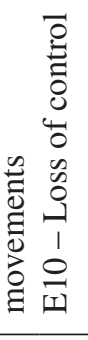 & 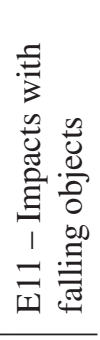 \\
\hline $\begin{array}{l}\text { H1 - Machinery } \\
\text { mobility }\end{array}$ & 0.652 & 0 & 3 & 0 & 9 & 0 & 3 & 3 & 9 & 3 & 3 & 0 \\
\hline $\begin{array}{l}\mathrm{H} 2 \text { - Moving } \\
\text { elements }\end{array}$ & 0.565 & 3 & 9 & 0 & 0 & 0 & 3 & 3 & 0 & 0 & 0 & 0 \\
\hline $\begin{array}{l}\mathrm{H} 3 \text { - Thermal } \\
\text { hazards }\end{array}$ & 0.130 & 0 & 0 & 9 & 0 & 3 & 0 & 0 & 0 & 0 & 0 & 0 \\
\hline $\begin{array}{l}\text { H4 - Stability } \\
\text { (machinery) }\end{array}$ & 0.348 & 0 & 0 & 0 & 9 & 3 & 0 & 0 & 3 & 3 & 9 & 0 \\
\hline $\begin{array}{l}\text { H5 - Environ- } \\
\text { ment (Dust, etc.) }\end{array}$ & 0.522 & 0 & 0 & 0 & 3 & 3 & 0 & 0 & 3 & 3 & 3 & 3 \\
\hline H6 - Noise & 0.304 & 0 & 0 & 0 & 0 & 3 & 0 & 9 & 0 & 0 & 3 & 0 \\
\hline H7 - Vibrations & 0.913 & 0 & 0 & 0 & 0 & 3 & 9 & 0 & 0 & 0 & 3 & 0 \\
\hline $\begin{array}{l}\text { H8 - Ergonomic } \\
\text { (Posture, etc.) }\end{array}$ & 0.478 & 0 & 0 & 0 & 0 & 9 & 0 & 0 & 9 & 0 & 0 & 0 \\
\hline $\begin{array}{l}\text { H9 - Ergonomic } \\
\text { (Commands) }\end{array}$ & 0.652 & 3 & 3 & 0 & 0 & 9 & 3 & 3 & 3 & 9 & 9 & 0 \\
\hline $\begin{array}{l}\text { H10 - Combina- } \\
\text { tion (stress) }\end{array}$ & 0.348 & 9 & 9 & 0 & 0 & 3 & 0 & 0 & 3 & 3 & 3 & 0 \\
\hline $\begin{array}{l}\text { Preliminary impo } \\
\text { factors of events }\end{array}$ & ortance & 6.78 & 12.1 & 131.17 & 10.5 & 17.8 & 8713.83 & 338.35 & 15.7 & 311.4 & 4817. & 1.57 \\
\hline $\begin{array}{l}\text { Preliminary prior } \\
\text { weights of hazarc }\end{array}$ & & 0.813 & 31.45 & 530.141 & 11.2 & 62.14 & 411.65 & 561.000 & & 11.37 & 752.0 & 0.188 \\
\hline
\end{tabular}

Table 6: Set of events.

\section{Set of events}

P1 - PTO protection

P2 - Transmission belt protection

P3 - Protection of the gearbox

P4 - Access handles

P5 - ROPS

P6 - Anti-vibration seat

P7 - Adequate muffler

P8 - Cabin filters

P9 - Seat's 'dead-man switch'

P10 - Seat's adjustment leverages
P11 - Seat's restraint system

P12 - Mechanical block/unblock of parking

P13 - On/Off locking differential system

P14 - Safety instructions

P15 - PPEs

P16 - Shredders' guards

P17 - Mower's guard

P18 - FOPS

P19 - Acoustic warning devices 
Table 7: Excerpt of the correlation matrix of the HoQ3.

\begin{tabular}{|c|c|c|c|c|c|}
\hline $\mathrm{HoQ}_{3}$ & 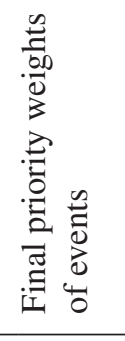 & 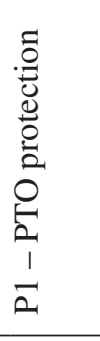 & 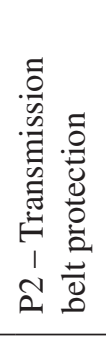 & 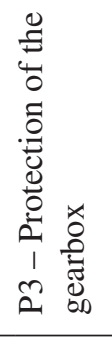 & 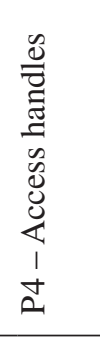 \\
\hline E1 - Contact with cutting parts & 0.9995 & 0 & 0 & 0 & 0 \\
\hline E2 - Contact with rotating parts & 1.7875 & 9 & 9 & 0 & 0 \\
\hline E3 - Contact with high temperature parts & 0.1670 & 0 & 0 & 9 & 0 \\
\hline E4 - Loss of stability & 2.0400 & 0 & 0 & 0 & 0 \\
\hline E5 - Contact with ejected objects & 0.0121 & 0 & 0 & 0 & 0 \\
\hline E7 - Exposure to vibrations & 0.0000 & 0 & 0 & 0 & 0 \\
\hline E6 - Exposure to noise & 0.0000 & 0 & 0 & 0 & 0 \\
\hline E8 - Slipping, falling & 0.1657 & 0 & 0 & 0 & 9 \\
\hline E9 - Unintended movements & 0.0194 & 0 & 0 & 0 & 0 \\
\hline E10 - Loss of control & 0.1546 & 0 & 0 & 0 & 0 \\
\hline E11 - Impacts with falling objects & 0.0005 & 0 & 0 & 0 & 0 \\
\hline \multicolumn{2}{|c|}{ Importance factors of preventive/protective measures } & 16.09 & 16.09 & 1.50 & 1.49 \\
\hline \multicolumn{2}{|c|}{ Priority weights of preventive/protective measures } & 0.541 & 0.541 & 0.051 & 0.050 \\
\hline
\end{tabular}

Differently from Ref. [1], in this case the calculation of the final priority weights of events did not consider costs related to events were not considered since this was not a goal of the study. Moreover, as for the calculation of the final importance factors and priority weights of events, the probability of occurrence of both fatal and non-fatal injuries, as well as the expected severity of injuries were estimated taking into account data provided by INAIL [26].

\section{DISCUSSION OF RESULTS}

As it can be seen in Fig. 3, the most relevant protective/preventive measures concern precisely:

1. P17 - Mower's guards;

2. P11 - Seat's restraint system;

3. P16 - Shredders' guard;

4. P14 - Safety instructions (tractor and equipment)

5. P1 - PTO protection and P2 - Transmission belt protection.

The priority of interventions reflects the status quo of the tractor and other equipment used by the company, e.g. in Fig. 4 the picture of the tractor's seat is shown, where the absence the seat belt can be noted. Thus, the present study confirmed the effectiveness of the use of the approach proposed by Bas [1] to perform risk assessment activities. The use of a focus group of experts (including users, machinery manufacturers/retailers and authorities) allowed us to 


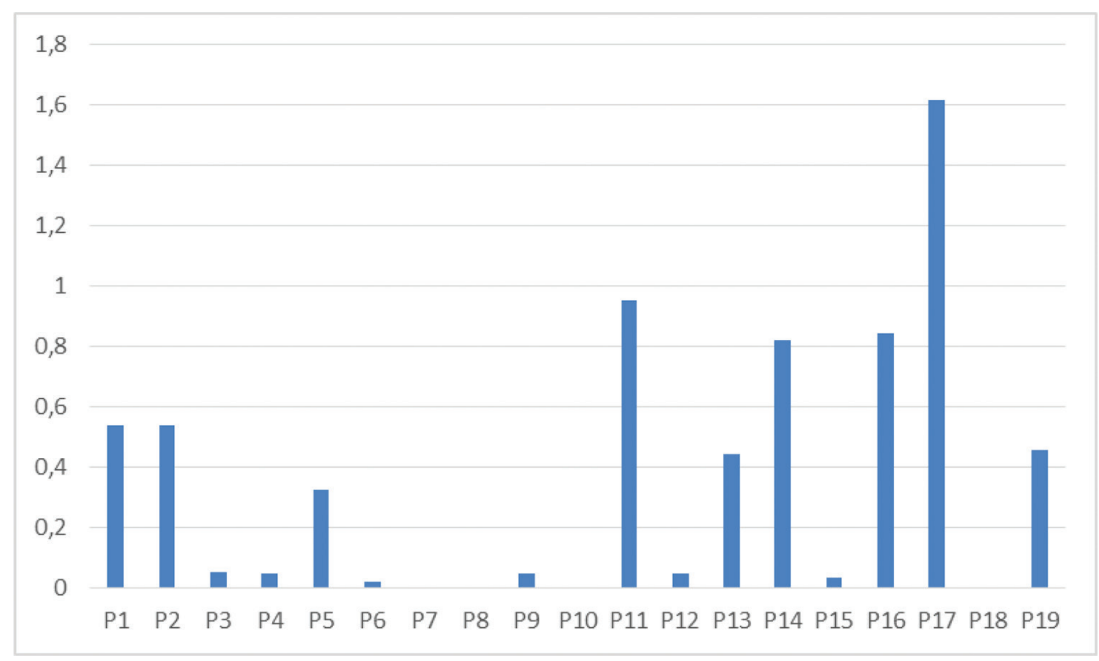

Figure 3: Priority weights of preventive/protective measures.

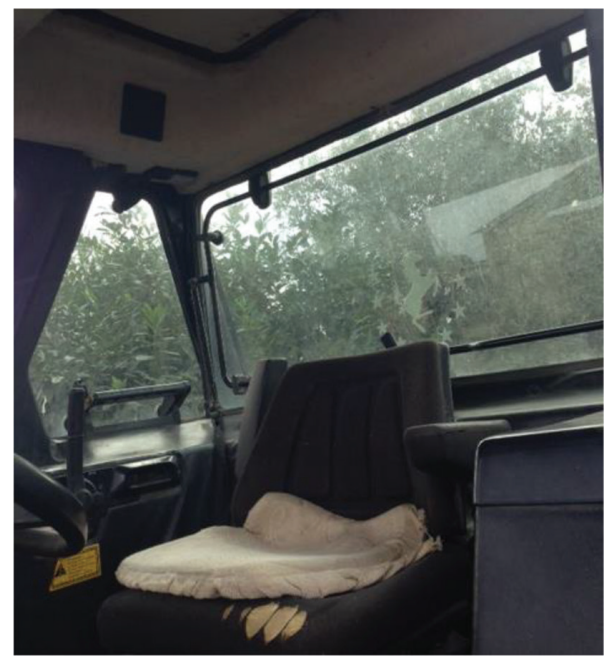

Figure 4: Details of the operator seat in the tractor's cabin.

identify and estimate all the relationships between tasks and hazards, hazards and events, as well as events and preventive/protective measures. In other words, the HoQ mechanism enables engineers to carry out a cause-effect analysis that provides an assessment of each interrelationship between tasks and hazards, hazards and events, and events compared with preventive/protective possible interventions.

Nevertheless, some limitations should be considered as well. Firstly, the assessment of the effects of the exposure to noise and vibrations could not be considered due to the lack of specific information. Secondly, the proposed methodology is based on the use of official statistics: the more these data are accurate the more the methodology can provide precise results. Then, it has to be noted that the relationship with cogent safety requirements is not 
provided, thus an additional effort is needed to provide solutions that are in compliance with current safety laws.

Finally, from a more general point of view, an additional limitation can be found in the risk of an incorrect assessment of qualitative characteristics and attributes, which is related to the use of the HoQ (as pointed out, for example, by Refs. [31-34]). To solve such a problem, as suggested by Ref. [1], the use of Fuzzy Logic could be considered.

\section{CONCLUSIONS AND FURTHER WORK}

In this study, a specific Safety-QFD methodology was implemented through its application to agricultural activities. More in details, the House of Quality was used following the approach proposed by Ref. [1] as a risk assessment tool, with the aim of identifying possible risks related with the use of a tractor and several equipment to carry out usual works in wheat farming.

Results achieved show that such a methodology can be used for the risk assessment effectively, allowing engineers to obtain the priority of interventions aimed at increasing the safety level of the working activities. Although these positive outputs, further research work is needed to exceed the above-mentioned limitations. In particular, a comparison with the traditional risk assessment approach suggested by the ISO 12100:2010 standard is foreseen. In addition, an easier-to-use tool for the assessment of safety costs, as the one proposed by Ref. [35] is currently being analysed.

\section{ACKNOWLEDGEMENTS}

Authors wish to thank Vincenzo Laurendi, PhD, and Daniele Puri, INAIL's researchers, for their support in the case study development.

\section{REFERENCES}

[1] Bas, E., An integrated quality function deployment and capital budgeting methodology for occupational safety and health as a systems thinking approach: the case of the construction industry. Accident Analysis \& Prevention, 68, pp. 42-56, 2014. https://doi.org/10.1016/j.aap.2013.10.005

[2] Eurostat, available at http://ec.europa.eu/eurostat/statistics-explained/index.php/Accidents_at_work_statistics, 2016 (Accessed 13 April 2017).

[3] Frank, A. L., McKnight, R., Kirkhorn, S. R. \& Gunderson, P., Issues of agricultural safety and health. Annual Review of Public Health, 25, pp. 225-245, 2004. https://doi.org/10.1146/annurev.publhealth.25.101802.123007

[4] Caffaro, F., Mirisola, A. \& Cavallo, E., Safety signs on agricultural machinery: pictorials do not always successfully convey their messages to target users. Applied Ergonomics, 58, pp. 156-166, 2017. https://doi.org/10.1016/j.apergo.2016.06.003

[5] Douphrate, D.I., Stallones, L., Lunner Kolstrup, C., Nonnenmann, M.W., Pinzke, S., Hagevoort, G.R. \& Jarvie, P., Work-related injuries and fatalities on dairy farm operations-a global perspective. Journal of Agromedicine, 18(3), pp. 256-264, 2013. https://doi.org/10.1080/1059924x.2013.796904

[6] Burgus, S. \& Duysen, E., Identifying topics and dissemination methods for agricultural safety and health messages. Safety, 3(3), p. 3, 2017.

https://doi.org/10.3390/safety3010003 
[7] Fargnoli, M., Vita, L., Gattamelata, D., Laurendi, V. \& Tronci, M., A reverse engineering approach to enhance machinery design for safety. Proceedings of the 12th International Design Conference - DESIGN 2012, pp. 627-636, 2012.

[8] Abubakar, M.S.A., Ahmad, D. \& Akande, F.B., A review of farm tractor overturning accidents and safety. Pertanika Journal of Science \& Technology, 18(2), pp. 377-385, 2010.

[9] Mayrhofer, H., Quendler, E. \& Boxberger, J., Occupational incidents with self-propelled machinery in Austrian agriculture. Journal of Agromedicine, 18(4), pp. 359-367, 2013. https://doi.org/10.1080/1059924x.2013.827997

[10] Cavallo, E., Ferrari, E., Bollani, L. \& Coccia, M., Attitudes and behaviour of adopters of technological innovations in agricultural tractors: a case study in Italian agricultural system. Agricultural Systems, 130, pp. 44-54, 2014.

https://doi.org/10.1016/j.agsy.2014.05.012

[11] Li, Z., Mitsuoka, M., Inoue, E., Okayasu, T. \& Hirai, Y., Development of stability indicators for dynamic Phase I overturn of conventional farm tractors with front axle pivot. Biosystems Engineering, 134, pp. 55-67, 2015. https://doi.org/10.1016/j.biosystemseng.2015.03.016

[12] Myers, M.L., Cole, H.P. \& Westneat, C., Injury severity related to overturn characteristics of tractors. Journal of Safety Research, 40, pp. 165-170, 2009. https://doi.org/10.1016/j.jsr.2009.02.007

[13] Myers, J.R. \& Hendricks, K.J., Agricultural tractor overturn deaths: assessment of trends and risk factors. American Journal of Industrial Medicine, 53(7), pp. 662-672, 2010. https://doi.org/10.1002/ajim.20775

[14] Fargnoli, M., Laurendi, V. \& Tronci, M., Design for safety in agricultural machinery. Proceedings of the 11th International Design Conference - DESIGN 2010, pp. 701-710.

[15] Donham, K.J. \& Thelin, A., Prevention of Illness and Injury in Agriculture. Agricultural Medicine: Rural Occupational and Environmental Health, Safety, and Prevention, John Wiley \& Sons, pp. 503-550, 2016.

[16] Lombardi, M., Guarascio, M. \& Rossi, G., The management of uncertainty: model for evaluation of human error probability in railway system. American Journal of Applied Sciences, 11(3), pp. 381-390, 2013. https://doi.org/10.3844/ajassp.2014.381.390

[17] Rautiainen, R.H., Ledolter, J., Donham, K.J., Ohsfeldt, R.L. \& Zwerling, C., Risk factors for serious injury in Finnish agriculture. American Journal of Industrial Medicine, 52(5), pp. 419-428, 2009.

https://doi.org/10.1002/ajim.20688

[18] Taattola, K., Rautiainen, R.H., Karttunen, J.P., Suutarinen, J., Viluksela, M.K., Louhelainen, K. \& Mäittälä, J., Risk factors for occupational injuries among full-time farmers in Finland. Journal of Agricultural Safety and Health, 18(2), pp. 83-93, 2012. https://doi.org/10.13031/2013.41348

[19] Liu, H.T. \& Tsai, Y.L., A fuzzy risk assessment approach for occupational hazards in the construction industry. Safety Science, 50, pp. 1067-1078, 2012. https://doi.org/10.1016/j.ssci.2011.11.021

[20] Kogler, R., Near accidents with agricultural vehicles, machinery and equipment in Austria in the year 2013. Agricultural Engineering International: CIGR Journal, 17(1), pp. 141-157, 2015. 
[21] Kogler, R., Quendler, E. \& Boxberger, J., Occupational accidents with agricultural machinery in Austria. Journal of Agromedicine, 21(1), 61-70, 2016. https://doi.org/10.1080/1059924x.2015.1075451

[22] Underwood, P. \& Waterson, P., Systemic accident analysis: examining the gap between research and practice. Accident Analysis \& Prevention, 55, pp. 154-164, 2013. https://doi.org/10.1016/j.aap.2013.02.041

[23] European Union. The 'Blue Guide' on the implementation of EU products rules 2016. Official Journal of the European Union, C 272/1, 59, 2016.

[24] INAIL, 'Informo' database concerning occupational accidents causing fatal and serious injuries, available at https://appsricercascientifica.inail.it/getinf/informo/home_ informo.asp, 2016 (accessed 13 April 2017).

[25] ASAPS, Database of the Association for traffic safety, available at http://www.asaps.it/, 2016 (accessed 13 April 2017).

[26] INAIL, Osservatorio INAIL sugli infortuni nel settore agricolo e forestale (National observatory on accidents in agricultural and forestry activities), 2017.

[27] Akao, Y., Quality Function Deployment: Integrating Customer Requirements into Product Design. Productivity Press, Cambridge, MA, 1990.

[28] ReVelle, J.B., Moran, J.W. \& Cox, C.A., The QFD Handbook, John Wiley \& Sons, Inc., 1998.

[29] Fargnoli M. \& Sakao T., Uncovering differences and similarities among Quality Function Deployment based methods in Design for X - benchmarking in different domains. Quality Engineering, pp. 1-23, 2016. https://doi.org/10.1080/08982112.2016.1253849

[30] Moores, B.M., Radiation safety management in health care - The application of Quality Function Deployment. Radiography, 12(4), pp. 291-304, 2006.

https://doi.org/10.1016/j.radi.2005.07.011

[31] Wang, X., Wang, L., Xu, X. \& Ji, P., Identifying employee turnover risks using modified quality function deployment. Systems Research and Behavioral Science, 31(3), pp. 398-404, 2014. https://doi.org/10.1002/sres.2282

[32] Carnevalli, J.A. \& Miguel, P.C., Review, analysis and classification of the literature on QFD-Types of research, difficulties and benefits. International Journal of Production Economics, 114(2), pp. 737-754, 2008. https://doi.org/10.1016/j.ijpe.2008.03.006

[33] Wang, C.H. \& Chen, J.N., Using quality function deployment for collaborative product design and optimal selection of module mix. Computers \& Industrial Engineering, 63, pp. 1030-1037, 2012. https://doi.org/10.1016/j.cie.2012.06.014

[34] Vinayak, K. \& Kodali, R., Benchmarking the quality function deployment models. Benchmarking: An International Journal, 20(6), pp. 825-854, 2013. https://doi.org/10.1108/bij-07-2011-0052

[35] Fargnoli, M. \& Pighini, U., SCRM: a new Design Tool for improving Safety Level of Mechanical Systems. Proceedings of the 14th International Conference on Engineering Design, ICED 03, pp. 553-554 (exec.summ.), 2003. 